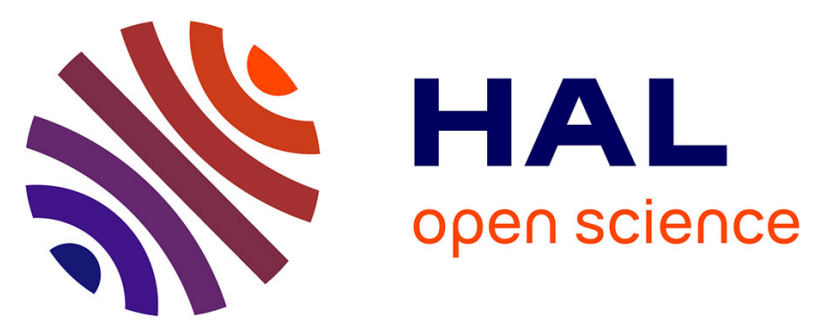

\title{
Variations of wood basic density with tree age and social classes in the axial direction within Pinus massoniana stems in Southern China
}

Xiangwen Deng, Liyun Zhang, Pifeng Lei, Wenhua Xiang, Wende Yan

\section{- To cite this version:}

Xiangwen Deng, Liyun Zhang, Pifeng Lei, Wenhua Xiang, Wende Yan. Variations of wood basic density with tree age and social classes in the axial direction within Pinus massoniana stems in Southern China. Annals of Forest Science, 2014, 71 (4), pp.505-516. 10.1007/s13595-013-0356-y . hal-01101774

\author{
HAL Id: hal-01101774 \\ https://hal.science/hal-01101774
}

Submitted on 9 Jan 2015

HAL is a multi-disciplinary open access archive for the deposit and dissemination of scientific research documents, whether they are published or not. The documents may come from teaching and research institutions in France or abroad, or from public or private research centers.
L'archive ouverte pluridisciplinaire $\mathbf{H A L}$, est destinée au dépôt et à la diffusion de documents scientifiques de niveau recherche, publiés ou non, émanant des établissements d'enseignement et de recherche français ou étrangers, des laboratoires publics ou privés. 


\title{
Variations of wood basic density with tree age and social classes in the axial direction within Pinus massoniana stems in Southern China
}

\author{
Xiangwen Deng $\cdot$ Liyun Zhang $\cdot$ Pifeng Lei $•$ \\ Wenhua Xiang • Wende Yan
}

Received: 21 June 2013 / Accepted: 16 December 2013 / Published online: 8 January 2014

(C) INRA and Springer-Verlag France 2014

\begin{abstract}
- Context Reliable estimates of wood density (WD) within individual trees could maximize the value of Pinus massoniana for specific end-use.

- Aim We examined and quantified the axial patterns of WD in trees with different social status in the stands.

- Methods Wood disks were sampled at the bottom, breast height, and middle of each $1-\mathrm{m}$ sections from 108 stems, harvesting from three social classes in subtropical forests. A mixed-effects model was designed to quantify axial variation. - Results The WD at different height was significantly different from the whole-stem WD (WWD) except the relative height of 0.1 . An overall decrease of $133.8 \mathrm{~kg} \mathrm{~m}^{-3}$ in WD was found from stem base to top. WD was significantly influenced by relative heights, tree age, and social class. WD of each relative height in mature trees was significantly higher than that of younger trees. Tree social class can affect WD development in the axial direction at age classes 2 and 3. Combining the fixed plus random effects, the final model explained $91 \%$ of the observed variation in WD.

- Conclusion The WD development patterns in the axial direction vary considerably among tree age, diameter at breast height, and social class. To distinguish and supply timber for
\end{abstract}

Handling Editor: Jean-Michel Leban

Contribution of the co-authors X.W. Deng: designed the experiment, collected data, wrote part of the paper, and revised the paper.

L.Y. Zhang: analyzed the results and wrote part of the paper.

P.F. LEI: conceived the ideas and revised the paper.

W.H. Xiang: conceived the ideas and improved the discussions.

W.D. Yan: coordinated the research project.

X. Deng $(\bowtie) \cdot$ L. Zhang $\cdot$ P. Lei $\cdot$ W. Xiang $\cdot$ W. Yan

Research Section of Forest Ecology, Central South University of

Forestry and Technology, Changsha, Hunan 410004, China

e-mail: dxwfree@126.com specific end-uses, we should use the axial variation in disk WD (DWD) instead of WWD directly. The accurate predictions of WD provided by the model could be used to optimally classify logs into different product classes and maximize economic benefits. We can use DWD at the relative height of 0.1 instead of WWD of a single tree.

Keywords Age class $\cdot$ Disk relative height $\cdot$ Hunan province $\cdot$ Pinus massoniana $\mathrm{L} \cdot$ Social class $\cdot$ Wood density

\section{Introduction}

An increased focus on sustainable forestry requires forest managers to consider both ecological and socioeconomic conditions (van Leeuwen et al. 2011). As a result of the increasing volume coming onto the market, it is essential to develop appropriate and efficient utilization of wood along the supply chain from juvenile wood to mature wood (Gil et al. 2010). Different types of products require different raw material properties (Nuutinen et al. 2009). Matching wood quality to markets can optimally maximize the value of the stands at the time of harvest and improve product uniformity, productivity, and profitability (Acuna and Murphy 2007). To specify the wood properties and to use trees more efficiently, it has become increasingly important to quantify the log dimensions and to determine external quality characteristics (i.e., knot size and distribution, taper, sweep, scarring, and decay). The measurement of wood density (WD) is a requirement in many wood product markets (Acuna and Murphy 2007).

Pinus massoniana is a principal tree species native to southern China (Zhang et al. 2012) and is the main commercial species used extensively for construction, railroad ties, mine timber, furniture, and wood pulp, among many other 
products. The species' rapid growth rate and good adaptation to poor conditions have led to its distribution over 1.13 million ha of forestland in China (Kuang et al. 2008). Given recent increases in raw wood consumption and the development of pulp and paper production, this species has drawn increasing interest pertaining to its utilization (Honnold 2009).

Since WD is correlated with strength and physical properties, it has been used as a determinant of wood quality and as an indicator of wood selection for utilization (Zobel and van Buijtenen 1989; Lindström 1996c). Species with different wood densities provide varying qualities that may be suitable for particular applications (Savidge 2003). Density varies between trees and within trees (Downes et al. 1997), and the latter influences the processing properties of each log (Raymond and Joe 2007). For example, a higher WD is required to produce wood panels with lower variability and superior mechanical properties (Hsu 1997), whereas lower WD is preferred by pulp and paper manufacturers (Downes et al. 1997). In-depth study of the stem WD could provide a good opportunity to maximize the value of harvested trees (Park et al. 2009).

A considerable body of literature has accumulated regarding density variation both in the radial direction (which increases from pith to bark), and in the axial direction (which decreases from butt to top) in conifers (Oliva et al. 2006; Ikonen et al. 2008; Antony et al. 2012). In particular, the decrease in WD in the axial direction can be more than $100 \mathrm{~kg} \mathrm{~m}^{-3}$ in pine (Repola 2006). Studies have confirmed that WD was affected by tree species, age, growth rate, site quality, environment condition, and silvicultural management such as fertilization and thinning (Lundgren 2004; Oliva et al. 2006; Ikonen et al. 2008; Zhang et al. 2012). For example, Lundgren (2004) found that effects of both fertilization and irrigation remained strong and significant for wood density, and an over $100 \%$ increase in ring width only corresponded to approximately a $20 \%$ decrease in wood density. Wilhelmsson et al. (2002) found that stem diameter, number of annual rings, and climatic indices accounted for 50 and $59 \%$ of WD variation in Picea abies and Pinus sylvestris, respectively. In contrast, the variation of WD in relation to the age class of tree, which was found to affect WD, has been described in only a few reports (Tsoumis and Panagiotidis 1980).

The social class of each individual tree represents its capacity to mobilize resources within its local environment (Henry et al. 2010). Lindström (1996a) demonstrated that crown development acts as a primary regulator of basic density in conifers. Kärkkäinen (1984) observed that the prediction of WD could be improved by taking tree class into account. Johansson (1993) reported that the WD of suppressed and co-dominant $P$. abies is higher than that of dominant trees. In relation to the effect of tree class on within-tree density, Lindström (1996c) found that the density increased at a faster rate when moving from the pith outward in suppressed
P. abies compared with dominant trees, and suggested that the tree class affects basic density development from pith outwards. Peltola et al. (2007) also studied the effects of tree class on the radial growth of $P$. sylvestris. However, to our knowledge, there is no result which has described WD variation in the axial direction along the stem for tree classes.

In the context of sustainable development, there is a strong demand for estimation of WD because it is a determinant of wood quality (Skovsgaard et al. 2011), and is also important in biomass estimation (Zhang et al. 2012). To P. massoniana, there have been several studies on the difference in WD in the axial direction (Jia et al. 2012), but little information is available on quantifying axial variation. The aim of this study was to develop a model to estimate WD along any given stem section of an individual $P$. massoniana tree. Therefore, the specific objectives were: (1) to examine the difference in WD between the whole stem and sections at specific heights, (2) to investigate the axial patterns of WD with regard to tree age and three different social classes (dominant, intermediate, and suppressed class), and (3) to determine the axial variation pattern by predicting the WD of each relative height.

\section{Materials and methods}

\subsection{Site and tree selection}

This study was carried out on a sample consisting of 108 P. massoniana trees, from the most productive region of Hunan Province (latitude $24^{\circ} 38^{\prime}$ to $30^{\circ} 08^{\prime} \mathrm{N}$ and longitude $108^{\circ} 47^{\prime}$ to $114^{\circ} 15^{\prime} \mathrm{E}$ ) in southern China (Zhang et al. 2012). The study area is in a humid subtropical monsoon climatic region with an annual precipitation of $1,400 \mathrm{~mm}$. The region is characterized by an average annual temperature of $17.4{ }^{\circ} \mathrm{C}$, ranging from -8 to $42.2^{\circ} \mathrm{C}$, an annual average evapotranspiration of $1,321.7 \mathrm{~mm}$, and a frost-free period of 278-300 days. The elevation of the stands ranges between 120 and $700 \mathrm{~m}$. The soil texture is well-drained, clay loam, red soil that developed on a slate parent rock. In order to encompass ranges of stand conditions and silvicultures, the sample trees were selected from plots of different qualities of natural secondary subtropical forest in this region. A total of 27 plots, each measuring $666.7(25.82 \mathrm{~m} \times 25.82 \mathrm{~m}) \mathrm{m}^{2}$, were selected in the study area. The main stand characteristics are summarized in Table 1.

Based on a complete inventory of the stand, we identified three crown classes on each plot, classified as dominant, intermediate, and suppressed. Dominant trees were defined as those whose crowns extended above the average level, intermediate trees referred to those whose crowns extended into the average level, and suppressed trees referred to those whose crowns were entirely below the average level (Zhang et al. 2012).

\section{פSpriager}


Table 1 Summary of the characteristics of 27 sampling plots

\begin{tabular}{|c|c|c|c|c|c|}
\hline & $\begin{array}{l}\text { Site } \\
\text { index }\end{array}$ & $\begin{array}{l}\text { Elevation } \\
(\mathrm{m})\end{array}$ & $\begin{array}{l}\text { Stand density } \\
\left(\mathrm{n} \mathrm{ha}^{-1}\right)\end{array}$ & $\begin{array}{l}\text { Average } \\
\text { DBH (cm) }\end{array}$ & $\begin{array}{l}\text { Average } \\
\text { height } \\
(\mathrm{m})\end{array}$ \\
\hline Minimum & 8 & 120 & 780 & 4.1 & 4.3 \\
\hline Maximum & 18 & 700 & 2,940 & 14.6 & 13.7 \\
\hline Mean & 10 & 272 & 1,840 & 8.31 & 7.80 \\
\hline $\begin{array}{l}\text { Standard } \\
\text { deviation }\end{array}$ & 3.2 & 182 & 480 & 2.81 & 2.83 \\
\hline CV (\%) & 35.2 & 66.7 & 26.1 & 33.8 & 36.3 \\
\hline
\end{tabular}

$D B H$ diameter at breast height, $C V$ coefficient of variation

One tree was randomly selected in each class, and thus three trees per plot were sampled. In the modeling data, 81 trees covering an age range of 5-29 years were collected for conversion into destructive sampling. The height of sample trees ranged from 2.3 to $18.6 \mathrm{~m}$. The diameter at breast height $(\mathrm{DBH})$ was $1.3 \mathrm{~m}$ above the ground, and ranged from 2.2 to $20.5 \mathrm{~cm}$. To validate the prediction, an additional tree was randomly selected and withheld for each plot. The 27 sampled stems varied from 7 to 27 years of age. The height and DBH of the validation trees ranged from 3.7 to $15.4 \mathrm{~m}$ and from 2.9 to $17.8 \mathrm{~cm}$, respectively. In order to explore the influence of age on the results, all of the sample trees were grouped into three age classes: age class 1, 5-10 years old (A1); age class 2, 1120 years old (A2); and age class 3, 21-29 years old (A3).

\subsection{WD measurement}

Sample trees were felled and stem dimensions, i.e. height, diameter at breast height $(1.3 \mathrm{~m})$, diameter at middle height, diameter at crown base, and height at the crown base, were measured. A marked line was made in the stem at the south direction, and then the stem was sectioned by a separated section of $1 \mathrm{~m}$. In the middle of each separated section, the bottom (in most cases, 3-5 cm above the ground) and the breast height, we sawed a knot-free cross-sectional disk, 30$50 \mathrm{~mm}$ thick. The fresh weight under the bark of each section and each disk were immediately measured. The disks were cut and planed the base cut surface, which produced a final surface that was smooth with clear ring boundaries. After cut and weighed in situ, the fresh disks were immediately placed in plastic bags to minimize moisture loss.

The disks were then transported to the laboratory for the average ring width (RW) measurement from the two vertical directions (east-west and south-north), as well as density determination using the water displacement method. Upon completion of these measurements, these disks were frozen at the end of each day. Then all the disks were oven dried at $105^{\circ} \mathrm{C}$ to a constant weight to determine disk dry weight and moisture content.
In our paper, the term wood density refers to basic density, defined as oven-dried mass divided by fresh volume, in kilograms per cubic meter (Megraw 1985). To calculate wholetree density, the fresh weight of each section was converted to dry weight based on the moisture content of each disks, and the fresh volume of each section was calculated from the length and diameters at each end using Smalian's formula (Pardé and Bouchon 1988). Disk WD (DWD) and wholestem WD (WWD) is the determination of total dry weight divided by total fresh volume of each section, as this was the basis of our calculation.

\subsection{Data analysis}

For the convenience of data analysis, we transformed the absolute height into relative height by using mathematical methods. The relative height was defined as $0,10,20,30$, $40,50,60,70$, and $80 \%$ of the absolute tree height. The wood density at each absolute height was changed into the nine relative heights by interpolation numerical method. The average WD was first calculated at each relative height. To verify the difference between WWD and DWD, we made specific comparisons between the WD of each relative height and the DWD of the corresponding stem, using paired two-sample $t$ tests. Analysis of variance (ANOVA), with Tukey HSD test, was carried out to evaluate WD variations at nine relative heights within the trees. Then, analysis of covariance (ANCOVA) was used to investigate the effects of relative height and social class on WWD. Tree age (total age of the tree), DBH, and RW (indicating the average radial growth rate) served as covariates to account for the differences between trees that grew under different conditions. With all the tree classes combined, post hoc Fisher's least significant difference (LSD) tests were used to determine the impact of age on WWD and WD for each relative height. All tests were performed at significance level of $\alpha=0.05$.

To examine the effect of tree social class on DWD of different heights, we calculated the means and standard deviations of WWD and DWD for each tree classes, as well as for each relative height in the case of DWD. The coefficients of variation $(\mathrm{CV})$ of WWD - a measure of variability for any given class - were estimated at each height for each of the three tree classes.

As the data followed a nested design structure (i.e., relative heights were nested within trees and plots), a linear mixedeffects model was used to account for the heterogeneity among plots, trees within plots, and relative heights within trees. In the model, the plot and tree level effects were combined at the tree level because the plot level was not significant. Disk WD and its gradient in the axial direction were expected to vary with tree age, $\mathrm{DBH}$, and relative height. The model selection was achieved using the restricted likelihoodratio test (LRT) and two commonly used information criteria, 
i.e., the Akaike's information criterion (AIC), and the Bayesian information criterion (BIC) (Pinheiro and Bates 2000). In addition, the model fit index $\left(R_{\mathrm{d}}^{2}\right)$, which was calculated following Parresol (1999), was applied to indicate the relative goodness of fit of each model. Only those parameters that were significant $(P<0.05)$ were retained in the final model. In the fixed part of the final model, the relative height, DBH, and tree age were used as independent variables. Following Repola (2006), a third-order polynomial was used to account for random variation at the tree level.

Finally, we attempted to validate this model by comparing its output with measured densities of the additional 27 sampled trees. Linear regression analyses were performed to determine the relationship of measured and predicted DWD that was calculated from the fixed and random effects for each relative height. The coefficient of determination $\left(R^{2}\right)$, the root mean square error (RMSE), and the variable significance were calculated. In addition, individual differences between measured DWD and the predictions of each relative height were assessed from paired two-sample $t$ tests. Statistical analyses were performed using SPSS statistical program package 13.0 (SPSS for Windows, Version 13.0, SPSS, Chicago, IL, USA).

\section{Results}

\subsection{DWD variations in the axial direction}

The average WWD was $477.2 \pm 42.8 \mathrm{~kg} \mathrm{~m}^{-3}$, ranging from 337.1 to $548.7 \mathrm{~kg} \mathrm{~m}^{-3}$. Within trees, density profiles strongly depend on the height position. An overall reduction in DWD of $133.8 \mathrm{~kg} \mathrm{~m}^{-3}$ from the stem base to the relative height of 0.8 was found, and corresponding to a CV of $37.9 \%$. We found a decrease in DWD with height that was greater for the lower half of the stem, with 2.3 and $1.0 \mathrm{~kg} \mathrm{~m}^{-3}$ per $1 \%$ increase in height, respectively (Fig. 1). Stem-base DWD has the lowest variability $(\mathrm{CV}=5.6 \%)$, and the stem top (relative height of $0.8)$ has the highest DWD variability $(\mathrm{CV}=12.1 \%)$. Paired two-sample $t$ tests revealed that WWD was significantly different from DWD at the studied relative heights $(P<0.001$, Fig. 1), except for the relative height of $0.1(t=0.841, \mathrm{df}=80$, $P=0.403$ ). However, only disks from the stem base had a significantly higher DWD than WWD.

From the ANCOVA model used to analyze the DWD variations at the nine relative heights, $60.8 \%$ of DWD variance could be accounted for in the model (Table 2). ANCOVA revealed a highly significant effect of tree age, relative height, social class, and DBH on DWD. As a covariate in the model, tree age had the greatest effect on DWD (Table 2). None of the interactions between relative height and age, social class, or DBH had a significant effect on DWD (Table 2).

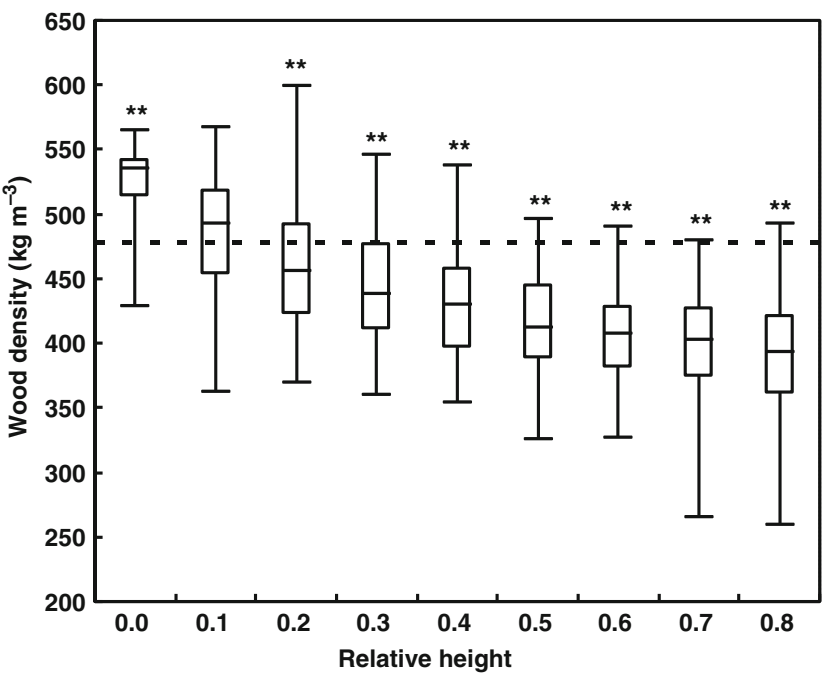

Fig. 1 Boxplot of axial variation of DWD along the stem for P. massoniana. Dashed line represents the weighted average DWD per tree. Box plots show the median, range, and 25 and $75 \%$ quartiles for DWD of different relative heights. ${ }^{*} P<0.001$ (significant differences between DWD at different heights relative to the stem DWD)

\subsection{DWD variations with age and tree social class}

Irrespective of tree social class, the average WWD increased as a function of age and was approximately $10 \%$ higher in the oldest age class compared to the youngest one (Fig. 2, $P<0.001)$. With regard to DWD, the patterns of decreasing density with height tend to be inconsistent within the studied age classes (Fig. 2). LSD analysis confirmed the results in Fig. 2, which showed that the DWD of A1 and A2 trees were significantly different $(P<0.05)$ from those of A3 trees for the nine relative heights. Furthermore, none of the nine relative

Table 2 ANCOVA of DWD for nine relative heights for 81 P. massoniana trees

\begin{tabular}{lllll}
\hline Source of variation & $d f$ & Mean square & $F$ value & $P$ value \\
\hline Model & 48 & 3,130 & 21.9 & $<0.001$ \\
Age & 1 & 60,300 & 42.4 & $<0.001$ \\
DBH & 1 & 7,270 & 5.10 & 0.024 \\
Hle & 8 & 21,800 & 15.3 & $<0.001$ \\
Social class & 2 & 6,960 & 4.89 & 0.008 \\
Hle $\times$ age & 8 & 1,900 & 1.34 & 0.221 \\
Hle $\times$ DBH & 8 & 1,540 & 1.08 & 0.373 \\
Social class $\times$ age & 2 & 228 & 0.160 & 0.852 \\
Social class $\times$ DBH & 2 & 2,110 & 1.48 & 0.228 \\
Social class $\times$ Hle & 16 & 870 & 0.611 & 0.876 \\
Error & 680 & 1,420 & & \\
Total & 729 & & & \\
$R^{2}$ & 0.608 & & & \\
\end{tabular}

$d f$ degrees of freedom, Hle the relative height levels, $R^{2}$ the coefficient of determination 


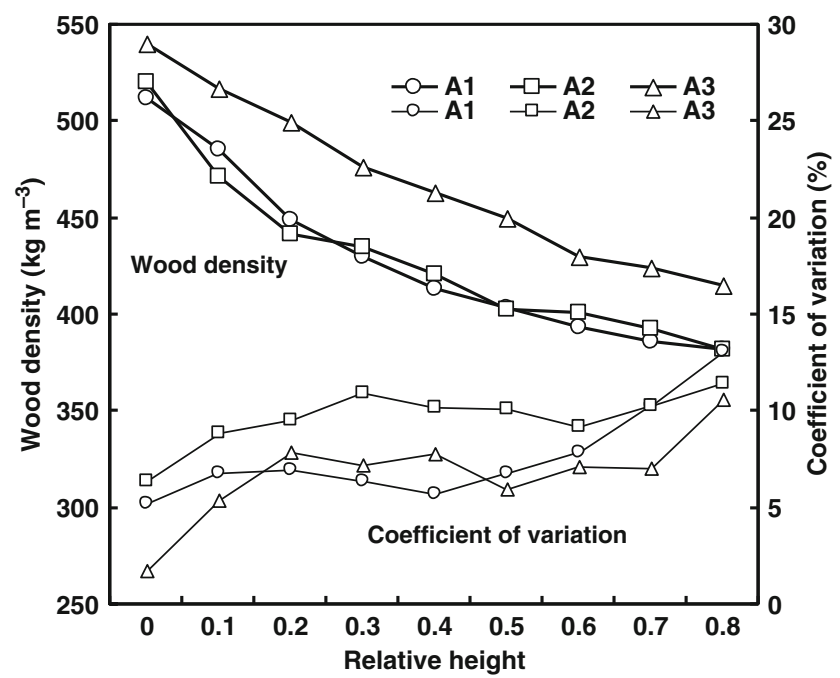

Fig. 2 Comparison of the magnitude and variability (CV) of DWD among the three age classes for the nine relative heights. $A 1$ trees 510 years old, $A 2$ trees 11-20 years old, $A 3$ trees 21-29 years old. Coefficient of variation represents standard deviations

heights showed significant increases in DWD between A1 and A2 trees. However, there was an increase in DWD between $\mathrm{A} 2$ and $\mathrm{A} 3$ trees. When analyzing each specific height, the $\mathrm{CV}$ increased with relative heights in all the three age classes. The DWD variations of A2 age tree from the stem base up to the relative height of 0.7 were higher than $\mathrm{A} 1$ and A3 age classes (Fig. 2).

With regard to the position of trees in a stand, suppressed trees had higher WWD than dominant and intermediate trees in A2 and A3 age classes (Table 3). However, in the A1 group, the WWD of suppressed trees was somewhat lower than that of the dominant and intermediate trees. There was no significant difference in WWD among A3 trees. Even so, there were significantly different in WWD among A1 age classes (between suppressed and intermediate trees) and A2 age classes (between suppressed and dominant trees). The WWD variability of suppressed trees was lower than that of dominant and intermediate A2 and A3 trees. Overall, the DWD of younger trees had larger variability (i.e., $\mathrm{CV}$ values) than older trees (Table 3).

The development of DWD in the axial direction along the stem was also analyzed in relation to both age and social class (Fig. 3). The results showed that only dominant A2 trees have consistently lower DWD along the stem (Fig. 3, b). Differences in DWD due to class were significant $(P<0.05)$ within each age class, with the exception of $\mathrm{A} 3$, in which the development of DWD of different classes, on average, was quite coincident with each other. Dominant trees exhibited significantly lower DWD than intermediate trees, only at a relative height of 0.8 (Fig. 3, c). In the axial direction along stems, the variability of DWD in the three classes was initially low, but gradually increased to a peak value near $12 \%$ at the relative height of 0.8 with regular oscillations (Fig. 3, d).

\subsection{Models for axial DWD variation}

We used both DBH and tree age as two independent variables in the model. The average RW (reflecting the growth rate) was not significant. The final model was:

$$
\begin{aligned}
\mathrm{DWD}_{i j} & =\left(b_{0}+b_{1} \mathrm{Age}_{i}+b_{2} \mathrm{DBH}_{i}+b_{3} \mathrm{Hle}_{i j}+b_{4} \mathrm{Hle}_{i j}^{2}+b_{5} \mathrm{Hle}_{i j}^{3}\right) \\
& +\left(\beta_{0 i}+\beta_{1 i} \mathrm{Hle}_{i j}+\beta_{2 i} \mathrm{Hle}_{i j}^{2}+\beta_{3 i} \mathrm{Hle}_{i j}^{3}+e_{i j}\right)
\end{aligned}
$$

where $\mathrm{DWD}_{i j}$ denotes the measurement of $\mathrm{DWD}, \mathrm{Hl}_{i j}$ is the relative height for tree $i$ at relative height $j(j=0.0,0.1,0.2,0.3$, $0.4,0.5,0.6,0.7$, and 0.8); $\mathrm{Age}_{i}$ is the age of tree $i ; \mathrm{DBH}_{i}$ is the DBH of tree $i ; b_{0} \ldots b_{4}$ are parameters of fixed effects; $\beta_{0 i}, \beta_{1 i}$, $\beta_{2 i}$, and $\beta_{3 i}$ are the intercept, first-, second-, and third-degree random coefficient effects, respectively, in tree $i$; and $e_{i j}$ is a

Table 3 Characteristics of three classes of sample trees illustrated by diameter at breast height (DBH), height (H), average ring width (RW), whole stem

\begin{tabular}{|c|c|c|c|c|c|c|}
\hline Age class & Class & DBH $(\mathrm{cm})$ & $\mathrm{H}(\mathrm{m})$ & WWD $\left(\mathrm{kg} \mathrm{m}^{-3}\right)$ & RW (cm) & CV of DWD (\%) \\
\hline \multirow[t]{3}{*}{1} & Dominant & $6.7 \pm 1.5 \mathrm{a}$ & $5.9 \pm 0.9 \mathrm{a}$ & $456 \pm 36.4 \mathrm{a}$ & $0.73 \pm 0.26 \mathrm{a}$ & 13.1 \\
\hline & Intermediate & $4.7 \pm 0.4 \mathrm{ab}$ & $4.5 \pm 0.4 \mathrm{a}$ & $479 \pm 28.0 \mathrm{ab}$ & $0.67 \pm 0.24 \mathrm{~b}$ & 14.8 \\
\hline & Suppressed & $3.5 \pm 2.2 \mathrm{~b}$ & $3.9 \pm 1.6 \mathrm{a}$ & $437 \pm 65.1 \mathrm{ac}$ & $0.60 \pm 0.20 \mathrm{c}$ & 10.0 \\
\hline \multirow[t]{3}{*}{2} & Dominant & $11.3 \pm 2.2 \mathrm{a}$ & $11.0 \pm 2.7 \mathrm{a}$ & $449 \pm 32.7 \mathrm{a}$ & $0.79 \pm 0.14 \mathrm{a}$ & 13.7 \\
\hline & Intermediate & $7.8 \pm 1.9 \mathrm{~b}$ & $7.9 \pm 2.5 \mathrm{~b}$ & $472 \pm 37.3 \mathrm{ab}$ & $0.65 \pm 0.16 b$ & 13.6 \\
\hline & Suppressed & $5.3 \pm 1.4 \mathrm{c}$ & $5.6 \pm 1.2 \mathrm{c}$ & $478 \pm 40.1 \mathrm{~b}$ & $0.52 \pm 0.11 \mathrm{c}$ & 12.9 \\
\hline \multirow[t]{3}{*}{3} & Dominant & $14.9 \pm 3.9 \mathrm{a}$ & $12.1 \pm 4.2 \mathrm{a}$ & $507 \pm 28.0 \mathrm{a}$ & $0.74 \pm 0.12 \mathrm{a}$ & 11.9 \\
\hline & Intermediate & $12.5 \pm 2.0 \mathrm{~b}$ & $10.3 \pm 3.3 \mathrm{ab}$ & $500 \pm 20.7 \mathrm{a}$ & $0.63 \pm 0.14 b$ & 10.4 \\
\hline & Suppressed & $9.3 \pm 1.7 \mathrm{c}$ & $9.1 \pm 1.6 \mathrm{~b}$ & $517 \pm 13.8 \mathrm{a}$ & $0.44 \pm 0.08 \mathrm{c}$ & 10.7 \\
\hline
\end{tabular}
DWD (WWD), and coefficient of variation of DWD in axial direction within trees (CV of DWD)

Different lowercase letters indicate statistically significant differences between classes within each age class $(P<0.05$; by ANOVA with Tukey HSD test); age class 1 is $5-10$ years old, age class 2 is $11-20$ years old, and age class 3 is $21-29$ years old of the sample trees 
Fig. 3 Comparison of the magnitude and variability $(\mathrm{CV})$ of DWD among tree classes for the nine relative heights at age classes $\mathrm{A} 1$ (a), A2 (b), and A3 (c). A1, trees 5-10 years old; $\mathrm{A} 2$, trees 11-20 years old; A3, trees $21-$ 29 years old. As the variability of the three classes have the same rules, subfigure $\mathbf{d}$ showed the variability at $\mathrm{A} 3$ age class, which was selected to express them
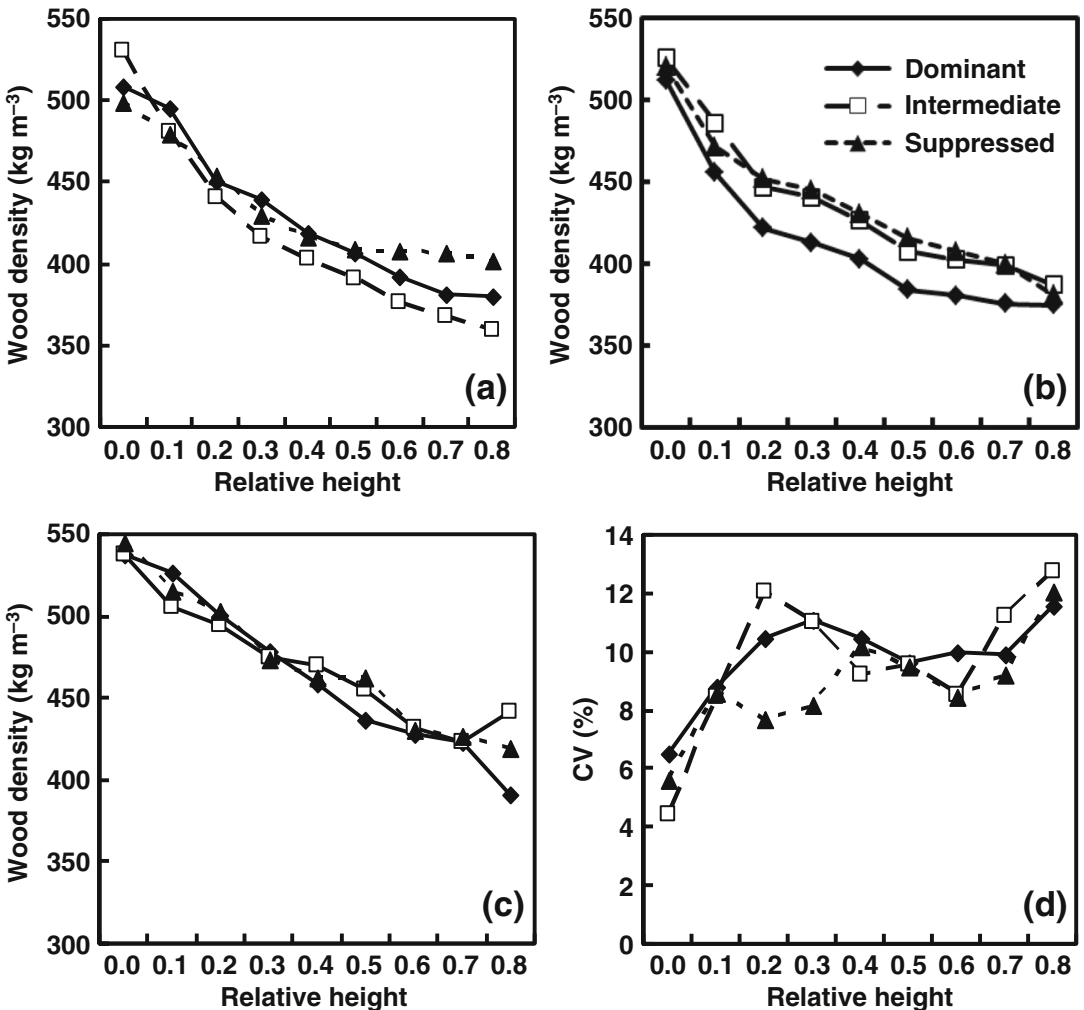

random parameter of tree $i$ at relative height $j$. The random "tree" effects $\left(\beta_{0 i}, \beta_{1 i}, \beta_{2 i}\right.$, and $\left.\beta_{3 i}\right)$ were assumed to follow a multivariate normal distribution $N(0, G)$ with a variancecovariance matrix $G(4 \times 4)$. The unknown fixed and random parameters were estimated by restricted maximum likelihood method. We next applied a linear mixedeffects model to estimate DWD at different relative heights. The model fit index informed us that model 1 has the highest $R^{2}$, and it increased at least 0.225 when the random effects were taken into account (Table 4). When the third-order polynomial regression form (Table 4, model 1) was applied, AIC, BIC, and LRT values decreased by 260,220 , and 270 , respectively, compared with the simple linear regression form (Table 4, model
5). Thus, model 1-which has the lowest AIC, BIC, and LRT values and the best fitness-was selected as the final model in the present study. In this final model, the DWD variation explained by the fixed effects was $58.1 \%$, with an additional $32.9 \%$ explained by the random tree effects (Table 4, model 1).

Estimates and significances of the final model parameters are provided in Table 5. According to the mixedeffect third-order polynomial regression, the relative height effect was highly significant $(P<0.001$, Table 5). A significant positive linear relationship was found between DWD and tree age in the model $(P<0.05)$, and DWD and DBH showed a significant negative relationship. The example simulations were conducted by using

Table 4 Comparison of the fitted linear mixed models on DWD, including the predictor variables examined and corresponding AIC, BIC, and LRT values and model fit index $\left(R_{\mathrm{d}}^{2}\right)$

\begin{tabular}{|c|c|c|c|c|c|c|c|}
\hline Model number & Fixed effects terms & Random effects terms & AIC & $\mathrm{BIC}$ & LRT & $R_{\mathrm{d}}^{2}$ (fixed effects) & $R_{\mathrm{d}}^{2}$ (fixed+random effects) \\
\hline 1 & $\mathrm{Age}+\mathrm{DBH}+\mathrm{Hle}+\mathrm{Hle}^{2}+\mathrm{Hle}^{3}$ & $\mathrm{Hle}+\mathrm{Hle}^{2}+\mathrm{Hle}^{3}$ & 6,900 & 6,960 & 6,880 & 0.581 & 0.910 \\
\hline 2 & $\mathrm{Age}+\mathrm{DBH}^{\mathrm{ns}}+\mathrm{Hle}+\mathrm{Hle}^{2}$ & $\mathrm{Hle}+\mathrm{Hle}^{2}$ & 6,980 & 7,070 & 6,970 & 0.580 & 0.874 \\
\hline 3 & $\mathrm{Age}+\mathrm{Hle}+\mathrm{Hle}^{2}$ & $\mathrm{Hle}+\mathrm{Hle}^{2}$ & 6,980 & 7,020 & 6,970 & 0.571 & 0.874 \\
\hline 4 & $\mathrm{DBH}+\mathrm{Hle}+\mathrm{Hle}^{2}$ & $\mathrm{Hle}+\mathrm{Hle}^{2}$ & 7,000 & 7,030 & 6,990 & 0.523 & 0.875 \\
\hline 5 & $\mathrm{Age}+\mathrm{DBH}+\mathrm{Hle}$ & Hle & 7,160 & 7,180 & 7,150 & 0.549 & 0.774 \\
\hline 6 & Age + Hle & Hle & 7,170 & 7,190 & 7,160 & 0.539 & 0.774 \\
\hline 7 & $\mathrm{DBH}+\mathrm{Hle}$ & Hle & 7,190 & 7,210 & 7,180 & 0.491 & 0.776 \\
\hline
\end{tabular}

$n s$ non-significant terms at $P<0.05$, AIC Akaike's information criterion, BIC Bayesian information criterion, LRT restricted likelihood-ratio test 
Table 5 Estimates, associated standard errors, and confidence limits $(95 \%)$ for fixed effects and variances of random effects for the final model

\begin{tabular}{llllll}
\hline Fixed effects & Parameters & Estimate & Standard error & $T$ test & $P$ value \\
& $b_{0}$ & 491.8 & 6.02 & 81.8 & $<0.001$ \\
& $b_{1}$ & 2.88 & 0.55 & 5.22 & $<0.001$ \\
& $b_{2}$ & -1.78 & 0.88 & -2.02 & 0.047 \\
& $b_{3}$ & -401.8 & 40.8 & -9.84 & $<0.001$ \\
Random effects & $b_{4}$ & 525.5 & 121 & 4.33 & $<0.001$ \\
& $b_{5}$ & -288.5 & 98.1 & -2.94 & 0.004 \\
& Parameters & Estimate & Standard error & $Z$ tests & $P$ value \\
& $\operatorname{Var}\left(\beta_{0 i}\right)$ & 398.5 & 128 & 3.11 & 0.002 \\
& $\operatorname{Var}\left(\beta_{1 i}\right)$ & 82,597 & 21,500 & 3.84 & $<0.001$ \\
& $\operatorname{Var}\left(\beta_{2 i}\right)$ & 712,219 & 190,000 & 3.75 & $<0.001$ \\
& $\operatorname{Var}\left(\beta_{3 i}\right)$ & 457,598 & 124,000 & 3.68 & $<0.001$ \\
& $e_{i j}$ & 444.1 & 31.4 & 14.1 & $<0.001$ \\
\hline
\end{tabular}

both fixed and random effects of the final model prediction compared with actual DWD development in the axial direction of different stems (Fig. 4). These simulations suggested that DWD in the axial direction was dependent on height location. Figure 5 shows the standardized residuals plotted against each of the three explanatory variables (Age, DBH, and Hle) in the model. There was no significant correlation between residuals and explanatory variables.

A comparison of predictions from the fixed and random effects of the final model versus correspondingly measured DWD from the validation dataset (DWD ranged from 305.1 to $548.1 \mathrm{~kg} \mathrm{~m}^{-3}$ ) is presented in Fig. 6. The mixed model developed for DWD predicted the range from low to high values reasonably well for all nine relative heights. Depending on the relative heights, the regression intercepts were between 44.482 and 173.767, and the slopes ranged from 0.665 to 0.884. $R^{2}$ values for the nine regression equations. These values were calculated from the fixed plus random effects that were between 0.664 and 0.972 , and the RMSE values that ranged from 7.164 to $15.922 \mathrm{~kg} \mathrm{~m}^{-3}$ (Fig. 6). According to the paired twosample $t$ tests for each relative height, there was no
Fig. 4 Example of the predicted DWD in the axial direction along the stem based on the model. $\mathbf{a}, \mathbf{b}$, and $\mathbf{c}$ are trees age $=15$ years, $\mathrm{DBH}=12 \mathrm{~cm} ;$ age $=15$ years, $\mathrm{DBH}=8 \mathrm{~cm}$; and age $=19$ years, $\mathrm{DBH}=8 \mathrm{~cm}$, respectively. Dashed lines represent the fixedeffects prediction, solid lines represent the fixed- and randomeffects prediction, and dots represent the observed values
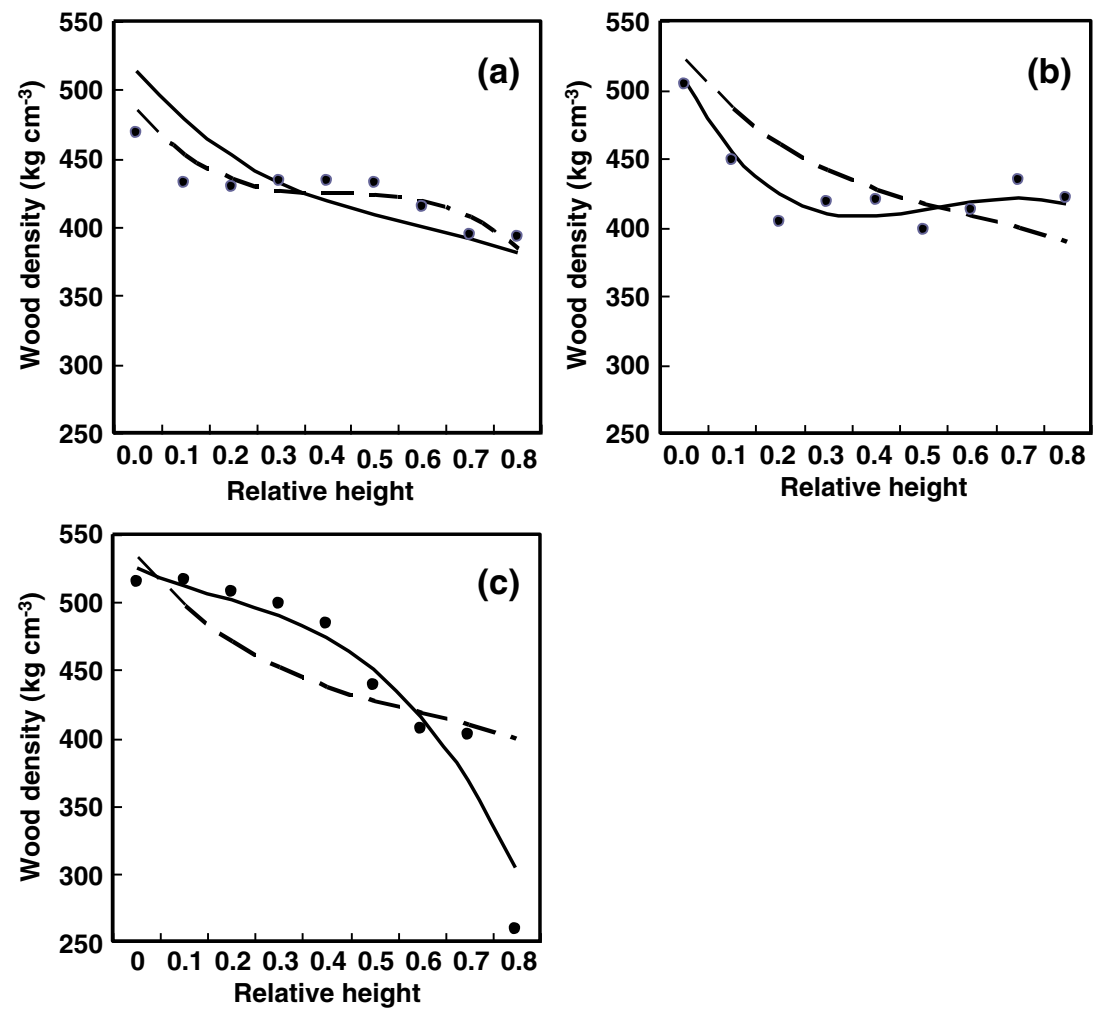

\section{b)}



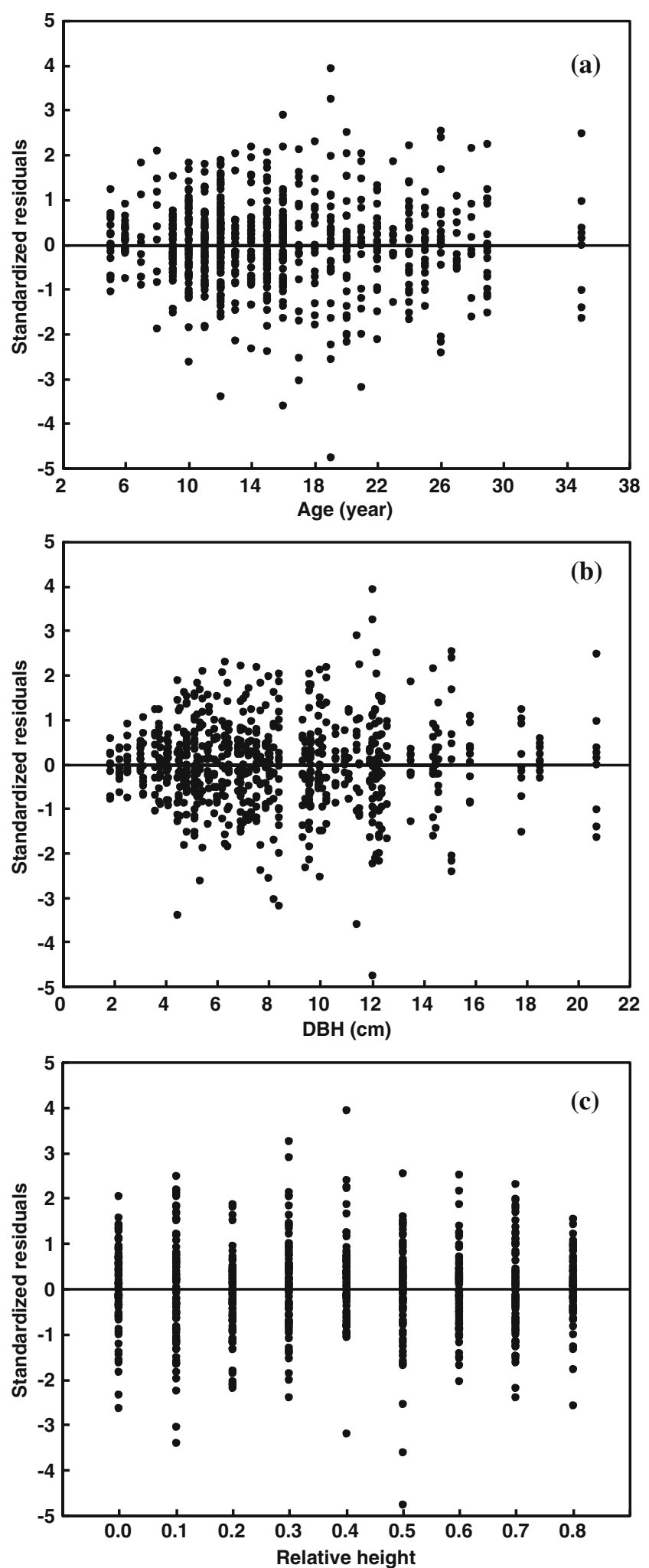

Fig. 5 Standardized residuals versus explanatory variables of age (a), $\mathrm{DBH}(\mathbf{b})$, and relative height (c) of the final model

significant difference $(-1.650 \leq t \leq 1.891, \mathrm{df}=26$, $0.07 \leq p \leq 0.832)$ between predicted and measured DWD.

\section{Discussion}

\subsection{Relationship between WWD and DWD}

The average WWD of $477.2 \mathrm{~kg} \mathrm{~m}^{-3}$ for $P$. massoniana in the present study is close to values reported in earlier studies for Pinus nigra and Pinus caribaea (Tsoumis and Panagiotidis 1980; Oluwafemi 2007). With respect to density variation in the axial direction within the stem, WWD was found to be significantly different from densities at all heights except for the relative height of 0.1 . The decreasing DWD with increasing height found in this study is in accordance with previous studies in other pine species (Hakkila 1979), including P. sylvestris (Repola 2006), P. nigra (Oliva et al. 2006), Pinus patula (Crous et al. 2009), and Pinus taeda (Antony et al. 2012). Wilhelmsson et al. (2002) found that the position in $P$. sylvestris had a more significant influence on WD than that of $P$. abies. In contrast, Ikonen et al. (2008) examined the tendency of WD to decrease from the stem base to the top in $P$. sylvestris, whereas in P. abies. WD first increases to some degree from the stem base upward and decreases again toward the tree top. The decreasing density was initially rapid and then slower in the axial direction. This result is in accordance with earlier studies which detected a rapid decrease in WD at the base with a slower decrease in the upper portion of the stem in pine (Hakkila 1979). Yao (1970) reported that the average specific gravity and latewood percentage of $P$. taeda varied more from the breast height of 30 to $50 \%$ height. In a recent study, Repola (2006) also found a steep WD gradient at the stem butt in P. sylvestris, and this is because the end products are made from individual heights and not from whole stems. The high variation observed demonstrates the importance of modeling WD at specific height locations, when considering wood quality assessment.

\subsection{Axial DWD variations with age and tree class}

The DWD increased with tree age (Fig. 2), which is in accordance with previous studies (Wilhelmsson et al. 2002; Oluwafemi 2007). A report on Pinus radiata in New Zealand (Cown et al. 1991) found that tree age was the determining factor for WD in all studied sites. The higher DWD of A3 trees could be related to the inclusion of trees that had entered the wood maturity phase, thus exhibiting a corresponding increase in WD. The anatomical interpretation of the variations of WD with tree age was that juvenile wood is usually characterized by shorter tracheid length and thinner cell walls than mature wood, provided by Zamudio et al. (2005) in pine species. According to the result, a long-term forest management strategy is necessary for increasing DWD and producing high-quality saw logs.

In the present study, the tree social class was found to influence both WWD and DWD, which is in line with 
Fig. 6 Relationship between measured and predicted wood densities from the mixed linear effects model for the nine height levels on the validation dataset $(n=27)$. These predictions of the population term are fixed + random term. The gray line represents 1:1 ratios
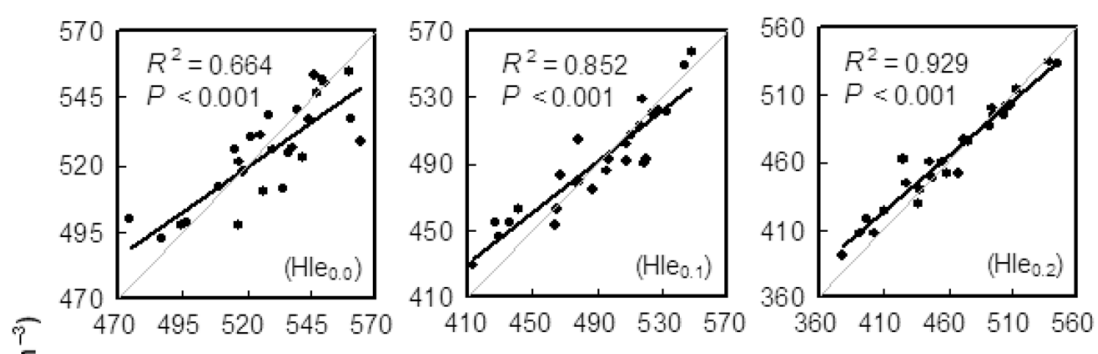

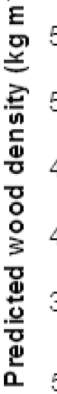
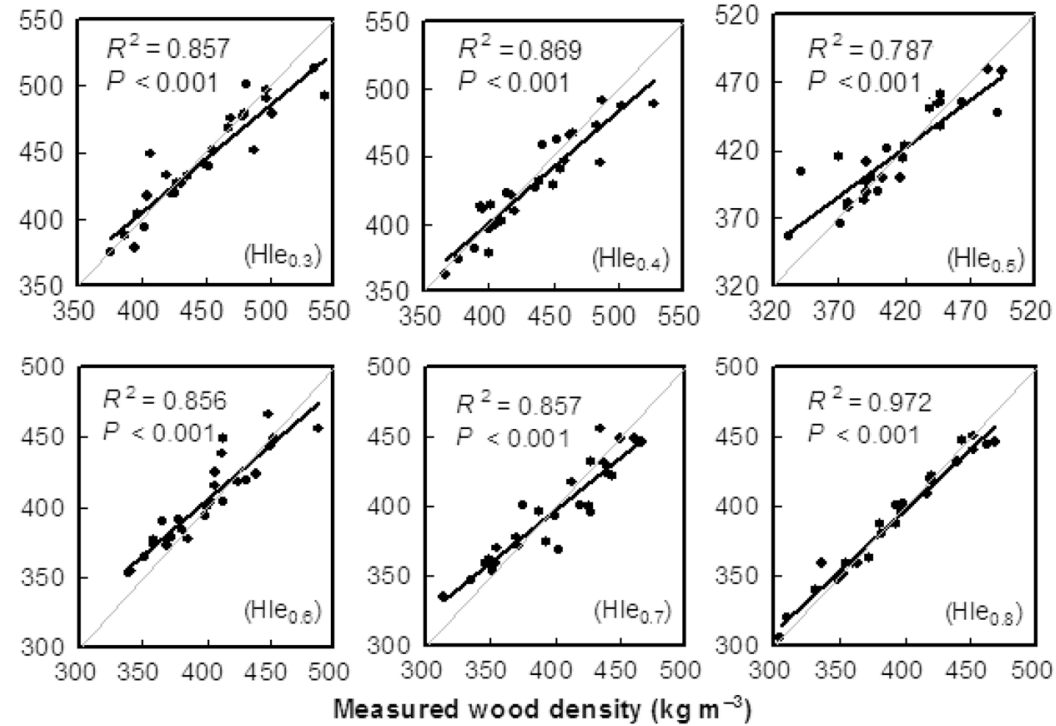

previous findings (Kärkkäinen 1984; Lindström 1996c). The higher WWD found in A2 and A3 suppressed and intermediate trees are in agreement with Lindström (1996c). However, in the A1 group, the WWD of suppressed trees was the lowest. The results indicate that the effect of tree class on WD is complicated, and there are many biological interpretations of the results. The difference of WD is mainly dependent on radial variation (Repola 2006). The density of latewood is higher than that of earlywood, based on the higher cell wall thickness and smaller diameter cell lumens of latewood compared with earlywood (Yao 1970). Therefore, WD is closely related to latewood percentage. Tsoumis and Panagiotidis (1980) found that the proportion of latewood was higher in suppressed P. nigra trees. Zhang et al. (1996) observed more dominant late- and earlywood tree growth every year, but with a lower latewood percentage and WD in Picea mariana. Ikonen et al. (2008) also reported a low proportion of earlywood, which leaded to the lower WD in dominant $P$. sylvestris trees. Peltola et al. (2007) reported that suppressed P. sylvestris trees grow less in diameter, but higher proportion of latewood which means that it has a higher WD than dominant and codominant trees. Nonetheless, for the age class 1 (A1 group) this does not work, just because of the suppressed, intermediate, and dominant trees may have the same ratio of the lateand earlywood width. Therefore, the WD was related to other reasons, like the tree age, $\mathrm{DBH}$, and so on.
The observed non-significant effect of growth rate on DWD is in line with reported findings in Pinus ponderosa by McKimmy and King (1980) and in Pinus pinaster by Gaspar et al. (2009). Cown et al. (1991) summarized several studies regarding the effect of growth rate on $P$. radiata $\mathrm{WD}$, concluding that there was no clear correlation between growth rate and density. On the contrary, there is a large number of works that demonstrated a relationship between WD and RW. Hakkila (1979) and Repola (2006) claimed that growth rate highly correlated with WD of $P$. sylvestris and $P$. abies, respectively. Zobel and van Buijtenen (1989) reported a negative correlation between mean WD and radial growth rate in $P$. abies and P. pinaster. The relationship between DWD and growth rate may be specific to individual populations, and there may be intra-specific genetic variation in this relationship (Hannrup et al. 2000; Peltola et al. 2007). In the present study, the other reason why the growth rate had no clear correlation with the WD is that growth rate was highly correlated with the tree age and DBH.

\subsection{Prediction of DWD}

Although several studies have been carried out regarding the axial variation of $\mathrm{WD}$, the variations have seldom been quantitatively modeled (Wilhelmsson et al. 2002). The mixedeffect model of the present study proved to be a suitable 
method for predicting DWD at different relative heights because variations in DWD both within (fixed effect) and between (random effect) trees were included. The consistency between predicted and measured DWD confirmed that the model enabled reliable and very accurate estimations of DWD, regardless of height levels within trees. The predictions of the mixed model delineated the patterns of axial variation of DWD by nine relative heights. The result could be related to the significant effects of tree age and social class on DWD. However, it should be noted that the DWD variation explained by the fixed part was less than $60 \%$ in the present study; an additional $30 \%$ of the total variation was explained by the random part. Similarly, Wilhelmsson et al. (2002) reported that the WD variation in P. abies and P. sylvestris explained by random effects was mostly attributed to variance among trees. The large degree of DWD variations among trees was at least partly controlled by genetic effects (Zobel and Jett 1995). In addition, when the model was tested on other stems for each height level, the percentage of explained variation in density ranged between 66.4 and 97.2. This may be due to differences in tree height, stem taper, and mean RW (Lindström 1996b), and differences due to tree dominance, silviculture, and site conditions (Gardiner et al. 2011). These varying elements were found to be statistically correlated with DWD. Though, all of these varying elements were not directly incorporated in the model. Still, the observed negative correlation between DBH and DWD was consistent with findings in $P$. radiata and P. sylvestris (Burdon and Low 1992; Hannrup et al. 2000). The DWD was best explained by the combined use of age, DBH, and relative height. There were two rational explanations: firstly, these independent variables in the models were quite easy to be measured; secondly, the average RW was sure to be highly correlated with age and DBH, particularly in the lower disks, which means it is hard to separate the effects of each variable in the analysis.

To effectively categorize wood, detailed information on its within-stem position is needed (Park et al. 2009). As demonstrated in this work and in a previous corresponding study by Repola (2006), WD was dependent on the relative height within the stem. Regarding the goal of better utilization of pine species, such as in the inside crown stem that can be used as man-made plank and papermaking industrial raw material should be lower WD. Thereby maximizing economic benefits, and allowing the proposed model for one to simulate the effects of heights by taking intra-tree variability into account. Accurate estimation of DWD of different stem sections should be used by timber processors to ensure that logs are used in the most appropriate and profitable manner by modifying processing practices or allocating logs to specific end-uses (Hamilton et al. 2007). Efficient utilization can be addressed through lumber specification, which is based on species, age, length, and size, as well as on the positions within the stem, according to different end-uses (Gil et al. 2010). The DWD evaluation in this study was limited to the data set calculated across the entire disk, and the specific cause of DWD variation associated with the proportion and density of latewood could not be established. Also, due to the fact that the DBH of sample trees ranged from 2.2 to $20.5 \mathrm{~cm}$, caution must be taken when equations are applied to trees outside of this range.

In addition, many biomass equations have been developed, where WD as an explanatory variable was also included (e.g., Basuki et al. 2009; Zhang et al. 2012). On the contrary, few studies have addressed the potential bias arising from axial variation in WD within stems (Fearnside 1997). In the present study, WD of different stem sections, rather than whole-tree values, may also be needed for accurate biomass estimations.

In conclusion, this study demonstrates the considerable amount of axial variation in DWD within P. massoniana and the significant effects of age, DBH, and social class. Most importantly, DWD at different relative heights, were found to have significant differences. At a relative height of 0.1, DWD was found to be approximately the same as WWD. When above the relative height of 0.1 , the DWD were lower than WWD. As a result, we can use the DWD at the relative height of 0.1 , which can be measured easily using a non-destructive method, instead of WWD. Both WWD and DWD increased with the tree age. But only when the tree grows up to A2 and A3 age classes, the tree social class could influence the WWD and DWD. Thus, we recommend using the axial variation in DWD to distinguish and supply timber for specific end-uses. To quantify the axial variation, a linear mixed-effects model was developed based on age, DBH, and relative height. The model developed in this study provides a simple method for estimating DWD at different heights along the stem of P. massoniana. Our approach avoided the approximation of using average whole-tree values, which oversimplifies the natural phenomenon, and took into account DWD variability in the axial direction. This greatly aids in the utilization of wood materials and in optimizing timber production to meet the required end-use properties for pine products.

Funding This study was supported by the State Forestry Special Fund for non-profit industries of China (grant number 201304317; 200804030), and the Introducing Advanced Technology Program (948 Program, grant number 2010-4-03).

\section{References}

Acuna MA, Murphy G (2007) Estimating relative log prices of Douglasfir through a financial analysis of the effects of wood density on lumber recovery and pulp yield. For Prod J 57:60-65

Antony F, Schimleck LR, Daniels RF (2012) Identification of representative sampling heights for specific gravity and moisture content in plantation-grown loblolly pine (Pinus taeda). Can J For Res 42:574 584. doi:10.1139/x2012-009 
Basuki TM, van Laake PE, Skidmore AK, Hussin YA (2009) Allometric equations for estimating the above-ground biomass in tropical lowland Dipterocarp forests. For Ecol Manag 257:1684-1694. doi:10. 1016/j.foreco.2009.01.027

Burdon RD, Low CB (1992) Genetic survey of Pinus radiata. 6: Wood. 595 properties: variation, heritabilities, and interrelationships with other traits. N Z J For Sci 22:228-245

Cown DJ, McConchie DL, Young GD (1991) Radiata pine-wood properties survey, FRI Bull. No. 50, Rotorua, New Zealand, 1991, $50 \mathrm{p}$

Crous JW, Morris AR, Scholes MC (2009) Effect of phosphorus and potassium fertiliser on stem form, basic wood density and stem nutrient content of Pinus patula at various stem heights. Aust For 72:99-111

Downes GM, Hudson IL, Raymond CA, Dean GH, Michell AJ, Schimleck LS, Evans R, Muneri A (1997) Sampling plantation eucalypts for wood and fibre properties. CSIRO Publishing, Melbourne

Fearnside PM (1997) Wood density for estimating forest biomass in Brazilian Amazonia. For Ecol Manag 90:59-89. doi:10.1016/ S0378-1127(96) 03840-6

Gardiner B, Leban J-M, Auty D, Simpson H (2011) Models for predicting the wood density of British-grown Sitka spruce. Forestry 84:119 132. doi:10.1093/forestry/cpq050

Gaspar MJ, Lousada, Rodrigues, Aguiar A, Almeida MH (2009) Does selecting for improved growth affect wood quality of Pinus pinaster in Portugal? For Ecol Manag 258:115-121. doi:10.1016/j.foreco. 2009. 03.046

Gil L, Tadesse W, Tolosana E, López R (2010) Eucalyptus species management, history, status and trends in Ethiopia. Proceedings from the Congress held in Addis Ababa, September, 15th-17th, pp $335-350$

Hakkila P (1979) Wood density survey and dry weight tables for pine, spruce and birch stems in Finland. Commun Inst For Fenn 96:1-59

Hamilton MG, Greaves BL, Potts BM, Dutkowski GW (2007) Patterns of longitudinal within-tree variation in pulpwood and solidwood traits differ among Eucalyptus globulus genotypes. Ann For Sci 64:831837. doi:10.1051/forest:2007064

Hannrup B, Ekberg I, Persson A (2000) Genetic correlations among wood, growth capacity and stem traits in Pinus sylvestris. Scand J For Res 15:161-170. doi:10.1080/028275800750014966

Henry M, Besnard A, Asante WA, Eshun J, Adu-Bredu S, Valentini R, Bernoux M, Saint-Andre L (2010) Wood density, phytomass variations within and among trees, and allometric equations in a tropical rainforest of Africa. For Ecol Manag 260:1375-1388. doi:10.1016/j. foreco. 2010.07.040

Honnold V (2009) Developments in the sourcing of raw materials for the production of paper. United States International Trade Commission. $\mathrm{J}$ In Commer Econ

Hsu EW (1997) Wood quality requirements for panel products. In: Zhang SY, Gosselin R, Chauret G (eds) Timber Management Toward Wood Quality and End-Product Value. Proceedings of the ATIA/IUFRO International Wood Quality Workshop, Quebec City, Part I, pp 7-10

Ikonen V-P, Peltola H, Wilhelmsson L, Kilpeläinen A, Väisänen H, Nuutinen T, Kellomäki S (2008) Modelling the distribution of wood properties along the stems of Scots pine (Pinus sylvestris L.) and Norway spruce (Picea abies (L.) Karst.) as affected by silvicultural management. For Ecol Manag 256:1356-1371. doi:10.1016/j. foreco.2008.06.039

Jia J, Huang YL, Yang ZQ (2012) Variation patterns of wood density on the two clonal seed orchard of Pinus massoninan. Guangxi Sci 19: 84-87 (In Chinese with English abstract)

Johansson K (1993) Influence of initial spacing and tree class on the basic density of Picea abies. Scand J For Res 8:18-27

Kärkkäinen M (1984) Effect of tree social status on basic density of Norway spruce. Silva Fenn 18:115-120
Kuang YW, Sun FF, Wen DZ, Zhou GY, Zhao P (2008) Tree-ring growth patterns of Masson pine (P. massoniana) during the recent decades in the acidification Pearl River Delta of China. For Ecol Manag 255: 3534-3540. doi:10.1016/j.foreco. 2008.02.036

Lindström H (1996a) Basic density in Norway spruce: Part I. A literature review. Wood Fiber Sci 28:15-27

Lindström H (1996b) Basic density in Norway spruce. Part II. Predicted by stem taper, mean growth ring width, and factors related to crown development. Wood Fiber Sci 28:240-251

Lindström H (1996c) Basic density in Norway spruce. Part III. Development from pith outwards. Wood Fiber Sci 28:391-405

Lundgren C (2004) Microfibril angle and density patterns of fertilized and irrigated Norway spruce. Silva Fenn 38:107-117

McKimmy MD, King JP (1980) Strength relationships in young ponderosa pine of known parentage. Wood Sci 12:165-167

Megraw RA (1985) Wood quality factors in loblolly pine. TAPPI Press, Atlanta, 89 p. ISBN 0-89852-048-7

Nuutinen T, Kilpeläinen A, Hirvelä H, Härkönen K, Ikonen V-P, Lempinen R, Peltola H, Wilhelmsson L, Kellomäki S (2009) Future wood and fibre sources-case North Karelia in eastern Finland. Silva Fenn 43:489-505

Oliva AG, Baonza Merino V, Fernández-Golfín Seco JI, Conde García M, Hermoso Prieto E (2006) Effect of growth conditions on wood density of Spanish Pinus nigra. Wood Sci Technol 40:190-204. doi: 10.1007/s00226- 005-0014-0

Oluwafemi OA (2007) Wood properties and selection for rotation length in Caribbean pine (Pinus caribaea Morelet) grown in Afaka, Nigeria. Am-Eurasian J Agric Environ Sci 2:359-363

Pardé J, Bouchon J (1988) Dendrométrie. ENGREF, Nancy

Park Y, Koubaa A, Brais S, Mazerolle MJ (2009) Effects of cambial age and stem height on wood density and growth of jack pine grown in boreal stands. Wood Fiber Sci 41:346-358

Parresol BR (1999) Assessing tree and stand biomass: a review with examples and critical comparisons. For Sci 45:573-593

Peltola H, Kilpeläinen A, Sauvala K, Räisänen T, Ikonen V-P (2007) Effects of early thinning regime and tree status on the radial growth and wood density of Scots pine. Silva Fenn 41:489-505

Pinheiro JC, Bates DM (2000) Mixed-effects models in S and S-PLUS. Springer, New York

Raymond CA, Joe B (2007) Patterns of basic density variation for Pinus radiata grown in south-west slopes region of NSW, Australia. N Z J For 37:81-95

Repola J (2006) Models for vertical wood density of Scots pine, Norway spruce and birch stems, and their application to determine average wood density. Silva Fenn 40:673-685

Savidge RA (2003) Tree growth and wood quality. In: Barnett JR, Jeronimidis G (eds) Wood quality and its biological basis. Blackwell, Oxford, pp 1-29

Skovsgaard JP, Bald C, Nord-Larsen T (2011) Functions for biomass and basic density of stem, crown and root system of Norway spruce (Picea abies [L.] Karst.) in Denmark. Scand J For Res 26:3-20. doi: 10.1080/02827581. 2011.564381

Tsoumis G, Panagiotidis N (1980) Effect of growth conditions on wood quality characteristics of Black pine (Pinus nigra Arn.). Wood Sci Technol 14:301-310. doi:10.1007/BF00383458

van Leeuwen M, Hilker T, Coops NC, Frazer G, Wulder MA, Newnham GJ, Culvenor DS (2011) Assessment of standing wood and fiber quality using ground and airborne laser scanning: a review. For Ecol Manag 261:1467-1478. doi:10.1016/j.foreco. 2011.01.032

Wilhelmsson L, Arlinger J, Spångberg K, Lundqvist S-O, Grahn T, Hedenberg Ö, Olsson L (2002) Models for predicting wood properties in stems of Picea abies and Pinus sylvestris in Sweden. Scand J For Res 17:330-350. doi:10.1080/02827580260138080

Yao J (1970) Influence of growth rate on specific gravity and other selected properties of loblolly pine. Wood Sci Technol 4:163-175. doi:10.1007/BF00571851 
Zamudio F, Rozenberg P, Baettig R, Vergara A, Yañez M, Gantz C (2005) Genetic variation of wood density components in a radiata pine progeny test located in the south of Chile. Ann For Sci 62:105114. doi:10.1051/forest:2005002

Zhang LY, Deng XW, Lei XD, Xiang WH, Peng CH, Lei PF, Yan WD (2012) Determining stem biomass of Pinus massoniana L. through variations in basic density. Forestry 85:601-609. doi:10.1093/ forestry/cps069
Zhang SY, Simpson D, Morgenstern EK (1996) Variation in the relationship of wood density with growth in 40 black spruce (Picea mariana) families grown in New Brunswick. Wood Fiber Sci 28: 91-99

Zobel BJ, van Buijtenen JP (1989) Wood variation-its causes and control. Springer, Berlin

Zobel B, Jett JB (1995) Genetics of wood production. Springer, Berlin, $337 \mathrm{p}$ 